\title{
LAPAROSCOPIC RADICAL PROSTATECTOMY IN PATIENTS WITH HIGH-RISK PROSTATE CANCER: FEASIBILITY AND SAFETY. RESULTS OF A MULTICENTRIC STUDY.
}

Authors: Virginia Varca1, Andrea Benelli', Davide Perri ${ }^{2}$, Ali Sedar Gozen ${ }^{3}$, Marcel Fiedler ${ }^{3}$, Alexandre de la Taille ${ }^{4}$, Giovanni Casazza ${ }^{5}$, Laurent Salomon ${ }^{4}$, Jens Rassweiler ${ }^{3}$, Andrea Gregori ${ }^{1}$, Franco Gaboardi ${ }^{6}$

1 Department of Urology, ASST-Rhodense, Garbagnate, Milan, Italy .

2 Department of Urology, University of Novara, Novara, Italy .

3 Department of Urology, SLK-Kliniken Heilbronn, University of Heidelberg, Heilbronn, Germany .

4 Urology Creteil, Hopital Henri Mondor, Île-de-France, France .

5 Department of biochemical and Clinical Science, University of Milan, Milan, Italy .

6 Division of Experimental Oncology, Department of Urology, Vita-Salute San Raffaele University of Milan , Milan, Italy

Running title: Laparoscopy for high risk prostate cancer

\section{Corresponding author}

Dr. Andrea Benelli

Department of Urology

ASST-Rhodense

Viale C. forlanini 95, Garbagnate Milanese, Milan

Phone: +393495592150

E-mail: abenelli@asst-rhodense.it 


\section{LAPAROSCOPIC RADICAL PROSTATECTOMY IN PATIENTS WITH HIGH-RISK PROSTATE CANCER: FEASIBILITY AND SAFETY. RESULTS OF A MULTICENTRIC STUDY.}

uthors: Virginia Varca1, Andrea Benelli ${ }^{1}$, Davide Perri ${ }^{2}$, Ali Sedar Gozen ${ }^{3}$, Marcel Fiedler ${ }^{3}$, Alexandre de la Taille ${ }^{4}$, Giovanni Casazza ${ }^{5}$, Laurent Salomon ${ }^{4}$, Jens Rassweiler ${ }^{3}$, Andrea Gregori 1, Franco Gaboardi ${ }^{6}$

${ }^{1}$ Department of Urology, ASST-Rhodense, Garbagnate, Milan, Italy

${ }^{2}$ Department of Urology, University of Novara, Novara, Italy

${ }^{3}$ Department of Urology, SLK-Kliniken Heilbronn, University of Heidelberg, Heilbronn, Germany

4Hopital Henri Mondor, Urology Creteil, Île-de-France, France

5Department of Statistics, University of Milan, Milan

6Department of Urology and Division of Experimental Oncology, Vita-Salute San Raffaele University of Milan, Italy

Running title: Laparoscopy for high risk prostate cancer

\section{Corresponding author}

Dr. Andrea Benelli 
Department of Urology

ASST-Rhodense

Viale C. forlanini 95, Garbagnate Milanese, Milan

Phone: +393495592150

E-mail: abenelli@asst-rhodense.it

\begin{abstract}
Introduction

In Western countries about $25 \%$ of prostate cancer $(\mathrm{PCa})$ are high risk tumors at presentation and its treatment is still a matter of debate among urologists. When the surgical treatment is chosen the proposal of a mini-invasive approach in still a dilemma due to the lack of data in literature. The aim of this study is to evaluate feasibility and safety of laparoscopic radical prostatectomy for high-risk prostate cancer.
\end{abstract}




\section{Material and methods}

The study included 1114 patients with high-riskPCa submitted to LRP between 1998 and 2014. Highrisk patients were defined according to D'Amico classification. We collected functional and oncological long terms outcomes and evaluated with univariate and multivariate analyses the role of predictive factors for survival and biochemical recurrence (BR).

\section{Results}

Mean age at the treatment was $62 \pm 8$ years; mean follow-up was $74 \pm 50$ months.

We obtained an OS at a mean follow-up of 74 months of $96.6 \%$ (1076 patients) and a DFS of $66.2 \%$ (737 patients). Age $(\mathrm{P}=0.0006), \mathrm{pT}(\mathrm{P}<0.0001), \mathrm{pN}(\mathrm{P}=0.0018)$ and surgical margins $(\mathrm{P}=0.0076)$ resulted as independent predictors for $\mathrm{BR}$ in multivariate analysis. $\mathrm{pN}(\mathrm{P}=0.0025)$ and $\mathrm{Gs}(\mathrm{P}=0.0003)$ are independent predictors for OS and CSS in a univariate analysis; just the Gs results significant in the multivariate model.

\section{Conslusion}

According to our encouraging data about oncological and functional outcomes we believe that radical prostatectomy represents an effective treatment for patients with high-risk prostate cancer and that laparoscopy is a safe approach offering a mini-invasive alternative to open surgery.

\section{INTRODUCTION}

Despite the introduction of aggressive screening policies in Western countries, about $25 \%$ of prostate cancers (PCa) are high risk tumors at presentation, [1] according to the D'Amico classification ( stage $>$ cT2c and/or PSA > $20 \mathrm{ng} / \mathrm{ml}$ and/or Gleason score > 7) $[1,2,3,4,5]$. The management of patients is complex, since no randomized studies have directly compared the oncological efficacy of surgery, radiation therapy and hormonal therapy. [6]. Moreover, when the surgical approach is chosen, 
surgeons have to face another dilemma: is a mininvasive technique such as laparoscopy or robotic surgery comparable to traditional open surgery? $[7,8,9]$.

Laparoscopic radical prostatectomy (LRP) was introduced in the late nineties, but to date only few series have shown long-term oncological results of this surgical approach and, moreover, this information is lacking especially in patients with high-risk disease. The importance of pure laparoscopic procedures is nowadays to underline in literature in order to encourage the use of $\underline{\text { mininvasive procedures in hospital that cannot afford a robot. }}$

The aim of our study is to evaluate the feasibility and safety of laparoscopic radical prostatectomy in terms of intra- and postoperative complications and long term oncological and functional results.

\section{MATERIAL AND METHODS}

\section{Patient population}

The study included 1114 consecutive patients with high-riskPCa who underwent LRP between May 1998 and May 2014 in three European Institutions: Henri Mondor University Hospital, Creteil, France (428 patients), SLK Clinic, Heilbronn, Germany (421 patients) and L. Sacco Hospital, Milan, Italy (265 patients). High-risk patients were defined according to D'Amico classification: PSA > $20 \mathrm{ng} / \mathrm{ml}$ and/or Gleason Score $\geq 8$ and/or clinical stage $>$ T2c.

PSA value was always measured before the prostate biopsy. Clinical stage was assigned before surgery. Pathologic grading was assessed according to the Gleason system and clinical stage was assigned according to the 2002 TNM system [1]. Patients with clinical souspicious of metastatic disease were staged with computed tomography (CT) or magnetic resonance (MRI). Bone scan was performed according to the EAU guidelines [1]. 


\section{Surgical procedure}

All the procedures were performed transperitoneally by expert surgeons who already accomplished their learning curve in laparoscopic radical prostatectomy.

Lymphadenectomy was performed according to the EAU guidelines indications at the moment of surgery; in most recent cases extended pelvic limphnode dissection (ePLND) was performed if the estimated risk for positive LNs exceeded $5 \%$ [1].

Data on limphadenectomy are available for 1022 patients $(91.7 \%)$ due to the retrospective nature of the study; most of the pNx patients underwent surgery in the late 90's when guidelines were still evolving about thisprocedure. Lymphadenectomy is performed before or after the prostatectomy depending on surgeon habits. If performed after it, lymphadenectomy is always performed before the vescico-urethral anastomosis in order to allow a better mobilization of the bladder without damaging the anastomosis. We always use a transperitoneal approach to minimize the risk of postoperative lymphocele formation.

$\underline{\text { Tamplates for standard dissection was the same in all the centers including obturator and external }}$ iliac nodes.

Due to the retrospective nature of the study and the variable definition of ePLND in literature the exact borders of the dissection is not always standardized in all the centers; all the procedures included obturator, external iliac and internal iliac nodes but not clear data are available about presacral, $\underline{\text { common iliac and presciatic nodes. }}$

\section{Post-operative evaluation}


The Clavien-Dindo complications grading system was used to evaluate intra- and perioperative complications. Postoperative follow-up included digital rectal examination (DRE) and serum PSA and was scheduled according to the scheme proposed by EAU PCa guidelines [1]. A telephonic update was realized in September 2014 for all patients. Biochemical recurrence (BCR) was defined as two consecutive PSA values $>0.2 \mathrm{ng} / \mathrm{ml}$.

Overall Survival (OS) was defined as the number of alive patients at last follow-up. Cancer Specific Survival (CSS) was defined as the number of patients alive after excluding deaths for other causes. Disease Free Survival (DFS) was defined as no evidence of BCR at last follow-up.

Urinary incontinence was evaluated in all patients and continence was defined as the use of 0 pads. We didn't evaluate the potency due to the risk characteristics of our population that exclude a nerve sparing approach according to the EAU guidelines; this decision was in 1998 and is still adherent to the guidelines where no specific recommendations for high risk tumor is made [1].

\section{Statistical analysis}

Categorical variables are reported as count (percentage), continuous variables are reported as mean ( \pm standard deviation) or median (range), as appropriate.

Kaplan-Meier analyses were used for the estimation of survival curves, considering BCR, cancerspecific and all cause mortality as the events of interest respectively. The log-rank test was used for comparison of survival curves between groups of patients.

Subsequently, univariate and multivariate Cox regression analyses were performed to establish the predictors of outcomes. Covariates were age, preoperative PSA, pathological Gleason score, surgical margins status, the use of lymphadenectomy, $\mathrm{pT}$ and $\mathrm{pN}$. Only those predictors which resulted 
significant in univariate analysis were introduced in the multivariate model. Thereafter, a backward elimination procedure was used to find the optimal predictive models. This set of analyses was performed for both BCR and cancer-specific mortality. For all the fitted Cox models, the proportional hazard assumption was checked. Hazard ratios (HR), with their 95\% confidence intervals (CI), were derived from the Cox models.

$\mathrm{P}$ values $<0.05$, two sided, were considered statistically significant. All the statistical analyses were performed with SAS statistical software (release 9.4; SAS Institute Inc., Cary, NC).

\section{RESULTS}

Patients characteristics, preoperative PSA, clinical stage and bioptic Gleason score are reported in Table 1.

\section{Complications}

Table 2 reports all the complications classified according to Clavien Dindo and respective treatments [7].

Overall 180 patients (16.2\%) presented a total of 186 complications. Blood transfusions represented the most common postoperative complication, a total of 132 cases (11.8\%). Excluding transfusions, number of patients with perioperative complications decreases to 54 patients $(4.8 \%)$.

The 11 patients presenting symptomatic lymphocele underwent percutaneous drainage.

Ten patients presented urethral stenosis at different point of follow-up; 6 of them underwent adjuvant radiotherapy. 
The overall complication rates were similar in patients undergoing e-PLND, st-PLND, and noPLND $(15.8 \%$ vs. $17.2 \%$ vs. $16.1 . \mathrm{P}=0.412)$.

\section{Oncological and functional outcomes}

Mean follow-up time was $74 \pm 50$ months.

In Table 2 are reported pathological results after LRP. There were 296 patients $(26.6 \%)$ with pT2 tumor, 769 (69\%) with pT3 tumor including 348 (31.2\%) cases of seminal vescicle invasion (pT3b); pT4 stage is reported in 49 cases (4.4\%). 118 patients $(10.6 \%)$ presented positive nodes and 383 (34.4\%) positive surgical margins. Most of the tumors (61.6\%) resulted with a Gleason score $\leq 7$. We obtained an OS at a mean follow-up of 74 months of $96.6 \%$ (1076 patients) and a DFS of $66.2 \%$ (737 patients).

The mean (SD) overall lymph node yield was 18.5 (5.7).

781 patients $(76.4 \%)$ underwent ePLND with a node yield of $19.1 ; 241$ patients $(23.6 \%)$ underwent stPLND with a node yield of 15.6. In Table 2 are shown pathologic data according to standard and $\underline{\text { extended procedures. }}$

In Table 3 are reported survival results stratified for stage, relaps and adjuvant treatment.

75 patients $(6.7 \%)$ presented disease persistence after surgery and are now alive and free of disease. Most of these patients (54) had a pT3 tumor; 17 a pT2 and just 4 a pT4. 536 patients $(48.1 \%)$ had a biochemical recurrence followed by adjuvant therapy; $527(98.3 \%)$ are still alive; $6(1.1 \%)$ died due to the tumor and $3(0.6 \%)$ for other causes. 500 patients $(44.9 \%)$ didn't receive any adjuvant treatment; most of them had a pT3 tumor (327), 155 had a pT2 and 18 a pT4. $472(94.4 \%)$ are still alive; $14(2.8 \%)$ died due to the tumor and 14 (2.8\%) due to other causes. As reported in Table 4 age 
$(\mathrm{P}=0.0006), \mathrm{pT}(\mathrm{P}<0.0001), \mathrm{pN}(\mathrm{P}=0.0018)$ and surgical margins $(\mathrm{P}=0.0076)$ resulted as independent predictors for BR in multivariate analysis.

Figures 1, 2, 3, 4 and 5 show survival curves with Kaplan-Meier model for DFS. Table 5 identifies $\mathrm{pN}(\mathrm{P}=0.0025)$ and $\mathrm{Gs}(\mathrm{P}=0.0003)$ as independent predictors for OS and CSS in a univariate analysis; just the Gs results significant in the multivariate model.

At a mean follow-up of 74 months 911 patients $(81.8 \%)$ were continent.

\section{Pathological results}

In Table 6 are reported clinical stagings and our final pathological results. 237 patients were cT1; 64 (27\%) pT2 and 173 (73\%) pT3. All the cT4 tumors were confirmed by final pathological examination.

\section{DISCUSSION}

Prostate cancer is characterized by heterogeneus presentation, extension and progression. The D'Amico classification allows a risk stratification helping the urologist to suggest the patient the best therapeutic opportunity. However it remains impossible to surely predict the behavior of the disease, its progression, treatment success and the risk of biochemical recurrence [9]. If it's generally not easy to choose the best approach it is even more difficult when we have to face an high risk tumor [10]. The surgical approach remains nowadays a matter of debate; radical prostatectomy plays an important role and it still very controversial if a mininvasive technique should be the standard of care $[4,5,11]$.

The safety of the procedure and its feasibility is strongly related to the complications. Gontero et al described radical prostatectomy for high risk patients as an acceptable procedure in terms of morbidity; with increasing in surgery time, transfusion rate, and lymphoceles [12]. Recently Soares et al described a large population of 1138 patients treated with LRP [13]. More than $80 \%$ were low- 
intermediate risk patients according to D'Amico classification. The overall complication rate was $5.2 \%$ (59 patients); which is lower than our $16.2 \%$ (180 patients); this group becomes significantly smaller if we exclude patients who needed blood transfusions, remains than 54 patients (4.8\%). Encouraging data emerge analyzing grade III complications; the author describes complication rate of $3.3 \%$, higher than our $1.4 \%$. Our results seems encouraging also compared with those presented by Di Benedetto et al: 446 patients with high risk tumor undergoing LRP; the author describes an overall complication rate of $7.6 \%$ and a grade III rate of $6.5 \%$ [14].

Certainly we report a significant transfusion rate (11\%); however this value is not so far from many results described in literature for LRP: Artibani et al describe a TR of $11 \%$ in a series of 71 patients, in a series of 219 patients the TR for Rassweiler et al is $9.6 \%$ and $9.8 \%$ for Rozet et al after 133 LRP $[15,16,17]$.

We can assume thatcomplications are relatively rare and most of them are not severe and also easy to treat.

The mean (SD) overall lymph node yield was 18.5 (5.7) which is comparable to data described in literature for open and robotic surgery [18].

$\underline{781 \text { patients }(76.4 \%) \text { underwent ePLND with a node yield of } 19.1 ; 241 \text { patients }(23.6 \%) \text { underwent }}$ $\underline{\text { stPLND with a node yield of 15.6. In Table } 2 \text { are shown pathologic data according to standard and }}$ extended procedures.

Our results are encouraging about the node yield if compared to literature; for an adeguate detection $\underline{\text { is described as necessary a node yield of at least } 13 \text { nodes removed during PLND of high risk PCa }}$ patients for robotic surgery by Sagalovich et al [19] and for retropubic prostatectomy by Briganti et al [20]. 
We obtained an overall survival of $96.6 \%$ (1076) and a disease free survival of $66.2 \%$ (737 patients) at a mean follow up of $74 \pm 50$ months which is acceptable if compared with results by Rassweiler et al. that described an OS of $94.9 \%$ and a DFS fo $78.2 \%$ in patients laparoscopically treated with organ confined tumors. Our OS and DFS are also comparable with those recently described by Borjian et al. [21] and Di Benedetto et al [14] for patients with high risk tumors treated with open and laparoscopic approach respectively. The last author presents a population of 446 patients and find out that the minimally invasive approach doesn't hide worse oncological and functional outcome if compared with an open approach. Probably the most important comparison should be made against radiotherapy that is described by randomized studies as the best approach for these tumors; our results are encouraging and seem comparable to the serie presented by Bolla et al. of RT and 3 years of androgen deprivation therapy [22]. Table 3 shows how an adjuvant therapy plays a positive role in survival rate in proportion to the higher $\mathrm{T}$ stage. The disease persistence occurred in 75 patients after surgery; they all received an adjuvant treatment and 74 of them were alive with no BR at the follow up. 500 patients didn't receive any adjuvant therapy after surgery; 438 of them result alive and free of disease at the follow up. We think our data we describe an encouraging outcome for patients recieveing adjuvant therapy; however it's not easy to state the best timing like Zwergel et al try to do; they describe a 5 year PSA progression-free survival rate of $76 \%$ in patients with immediate hormonal treatment an of 53\% in patients with surveillance and delayed hormonal therapy [23].

Our uni- and multivariate analysis show that $\mathrm{pT}$ and $\mathrm{pN}$ are directly proportional to the probability of BR. Positive surgical margins are also a positive predictor for BR. The age at the surgery is inversely proportional; younger patients are more likely to present BR after surgery. These correlations are well described in Kaplan-Mayer courves. On the contrary, in Zwergel's analysis none of the investigated parameters was demonstrated to be of independent prognostic significance for tumor-specific survival but in an importantly smaller population. The data regarding $\mathrm{pN}$ confirms the importance of lymphadenectomy in these patients as described by Briganti et al. developing the well known 
nomogram and by Bader who analyzed the survival of patients with positive nodes [24,25]. Our data seems in line with the growing evidence that ePLND plays not only a prognostic role but also a therapeutic one in high risk patients, there is now level 1 evidence as reported in literature [26].

Just $\mathrm{pN}$ and $\mathrm{pGS}$ resulted as predictors for overall- and cancer specific survival; they are obviously inversely proportional.

The comparison of clinical and pathological stage brought interesting results. We reported a clinical understaging in about $30 \%$ of cT2 and in $100 \%$ of cT1. That means that patients clinically considered as low or intermediate risk could reveal an high risk tumor, it plays a foundamental role in defining the disease and approach it with the best treatment.

\section{CONCLUSIONS}

Our work brings encouraging data about the oncological and functional safety of laparoscopic radical prostatectomy even in high-risk patients. We believe that radical prostatectomy represents an effective treatment for patients with high risk prostate cancer and that laparoscopy is a safe approach offering a mini-invasive alternative to open surgery. It permits also to a better identification and characterization of the disease leading to a more accurate evaluation of the prognosis and planning of the follow-up. We therefore propose a more comprehensive use of this technology in all patients who are candidates for surgery.

\section{Author Disclosure Statement}

All the authors of the manuscript disclose any commercial associations that might create a conflict of interest in connection with the submitted manuscript.

No competing financial interests exist 


\section{REFERENCES}

1. Heidenreich A, Aus G, Bolla M, et al. EAU guidelines on prostate cancer. Eur Urol 2008;53:68- PubMed ;80.

2. Spahn M., Joniau S., Gontero P. et al. Outcome Predictors of Radical Prostatectomy in Patients With Prostate-Specific Antigen Greater Than $20 \mathrm{ng} / \mathrm{ml}$ : A European Multi-Institutional Study of 712 Patients EUROPEAN UROLOGY 58 (2010) 1-7.

3. Cooperberg MR, Lubeck DP, Mehta SS, Carroll PR. Time trends in clinical risk stratification for prostate cancer: implications for outcomes (data from CaPSURE). J Urol 2003;170:S21-5, discussion S26-7.

4. Yossepowitch O, Eggener SE, Serio AM, et al. Secondary therapy, metastatic progression, and cancerspecific mortality in men with clinically high-risk prostate cancer treated with radical prostatectomy. Eur Urol 2008;53:950- PubMed ;9.

5. Inman BA, Davies JD, Rangel LJ, et al. Long-term outcomes of radical prostatectomy with multimodal adjuvant therapy in men with a preoperative serum prostate-specific antigen level $>$ or $=50 \mathrm{ng} / \mathrm{mL}$. Cancer 2008;113:1544- PubMed ;51. 
6. SA. Boorjian, RJ Karnes, R Viterbo et al. Long-Term Survival After Radical Prostatectomy Versus External Beam Radiotherapy for Patients with High-Risk Prostate Cancer. Cancer. 2011 July 1; 117(13): 2883-2891.

7. Lange PH. Is surgery good for advanced localised prostate cancer? It's time to find out! Eur Urol 2007;51:873- PubMed ;5.

8. Zwergel U, Lehmann J, Wullich B, et al. Lymph node positive prostate cancer: long-term survival data after radical prostatectomy. J Urol 2004;171:1128- PubMed ;31.

9. Gontero P, Marchioro G, Pisani R, et al. Is radical prostatectomy feasible in all cases of locally advanced non-bone metastatic prostate cancer? Results of a single-institution study. Eur Urol 2007;51:922- PubMed ;30.

9. Bastian PJ, Gonzalgo ML, Aronson WJ, et al. Clinical and pathologic outcome after radical prostatectomy for prostate cancer patients with a preoperative GS of 8 to 10 . Cancer 2006;107:1265- PubMed ;72.

10. Thompson I, Thrasher JB, Aus G, et al. Guideline for the management of clinically localized prostate cancer: 2007 update. J Urol 2007;177:2106- PubMed ;31. 
11. Gerber GS, Thisted RA, Chodak GW, et al. Results of radical prostatectomy in men with locally advanced prostate cancer: multi---institutional pooled analysis. Eur Urol 1997;32(4):385 PubMed ---90.

12. Gontero P, Marchioro G, Pisani R, et al. Is radical prostatectomy feasible in all cases of locally advanced non-bone metastatic prostate cancer? Results of a single institution study. Eur Urol 2007;51:922- PubMed ;30

13. R Soares, A Di Benedetto, Z Dovey, S Bott, RG. McGregor and CG. Eden. Minimum 5-year follow-up of 1138 consecutive laparoscopic radical prostatectomies BJU Int 2015; 115: 546-553.

14. A Di Benedetto, R Soares, Z Dovey, S Bott, R G. McGregor and C G. Eden. Laparoscopic radical prostatectomy for high-risk prostate cancer. BJU Int 2015; 115: 780-786.

15. Artibani W, Grosso G, Novara G, et al: Is laparoscopic radical prostatectomy better than traditional retropubic radical prostatectomy?

An analysis of perioperative morbidity in two contemporary series in Italy. Eur Urol 2003; 44: 401- PubMed ;406. 
16. Rassweiler J, Seemann O, Schulze M, Teber D, Hatzinger M, Frede T: Laparoscopic versus open radical prostatectomy: a comparative study at a single institution. J Urol 2003; 169: 1689- PubMed ; 1693.

17. Rozet F, Jaffe J, Braud G, et al: A direct comparison of robotic assisted versus pure laparoscopic radical prostatectomy: a single institution experience. J Urol 2007; 178: 478- PubMed ;482.

18. D. Truesdale, B.A., Daniel J. Lee, M.D., Philippa J. Cheetham, M.D., Gregory W. Hruby, M.S., Andrew T. Turk, M.D., and Ketan K. Badani, M.D. Assessment of Lymph Node Yield After Pelvic Lymph Node Dissection in Men with Prostate Cancer: A Comparison Between Robot-Assisted Radical Prostatectomy and Open Radical Prostatectomy in the Modern Era Matthew JOURNAL OF ENDOUROLOGY Volume 24, Number 7, July 2010.

19. Sagalovich D, Calaway A, Srivastava A, Sooriakumaran P, Tewari AK. Assessment of required nodal yield in a high risk cohort undergoing extended pelvic lymphadenectomy in robotic-assisted radical prostatectomy and its impact on functional outcomes. BJU Int 2013;111:85-94 PubMed .

20. Briganti A, Chun FK, Salonia A, Gallina A, Zanni G, Scattoni V, et al. Critical assessment of ideal nodal yield at pelvic lymphadenectomy to accurately diagnose prostate cancer nodal metastasis in patients undergoing radical retropubic prostatectomy. Urology 2007;69:147-51 PubMed . 
21. SA. Boorjian, RJ Karnes, R Viterbo, LJ Rangel, E J Bergstralh, EM Horwitz, ML Blute and MK Buyyounouski. Long-Term Survival After Radical Prostatectomy Versus External Beam Radiotherapy for Patients with High-Risk Prostate Cancer. Cancer. Author Manuscript. Available in PMC 2012 July 10.

22. Bolla M, Gonzalez D, Warde P, Dubois JB, Mirimanoff RO, Storme G, Bernier J, Kuten

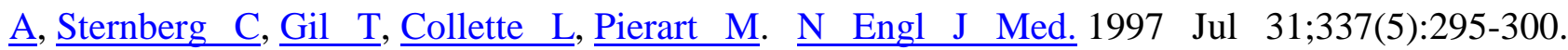
Improved survival in patients with locally advanced prostate cancer treated with radiotherapy and goserelin.

23. Zwergel U, Suttmann H, Schroeder T, Siemer S, Wullich B, Kamradt J, Lehmann J, Stoeckle M. $\underline{\text { Outcome of prostate cancer patients with initial PSA\&gt; or }=20 \mathrm{ng} / \mathrm{ml} \text { undergoing radical }}$ prostatectomy. Eur Urol. 2007 Oct;52(4):1058-65. Epub 2007 Mar 28.

24. Briganti A, Larcher A, Abdollah F, et al. Updated Nomogram Predicting Lymph Node Invasion in Patients with Prostate Cancer Undergoing Extended Pelvic Lymph Node Dissection: The Essential Importance of Percentage of Positive Cores. Eur Urol 2012 Mar;61(3):480-7. 
25. Bader P, Burkhard FC,Markwalder R, Studer UE. Disease progression and survival of patients with positive lymph nodes after radical prostatectomy: is there a chance of cure? J Urol 2003;169:849- PubMed ;54.

26. Ji J, Yuan H, Wang L, Hou J. Is the impact of the extent of lymphadenectomy in radical prostatectomy related to the disease risk? A single center prospective study. J Surg Res 2012; 178: 779- PubMed ;88 
Figure 1: pathological T

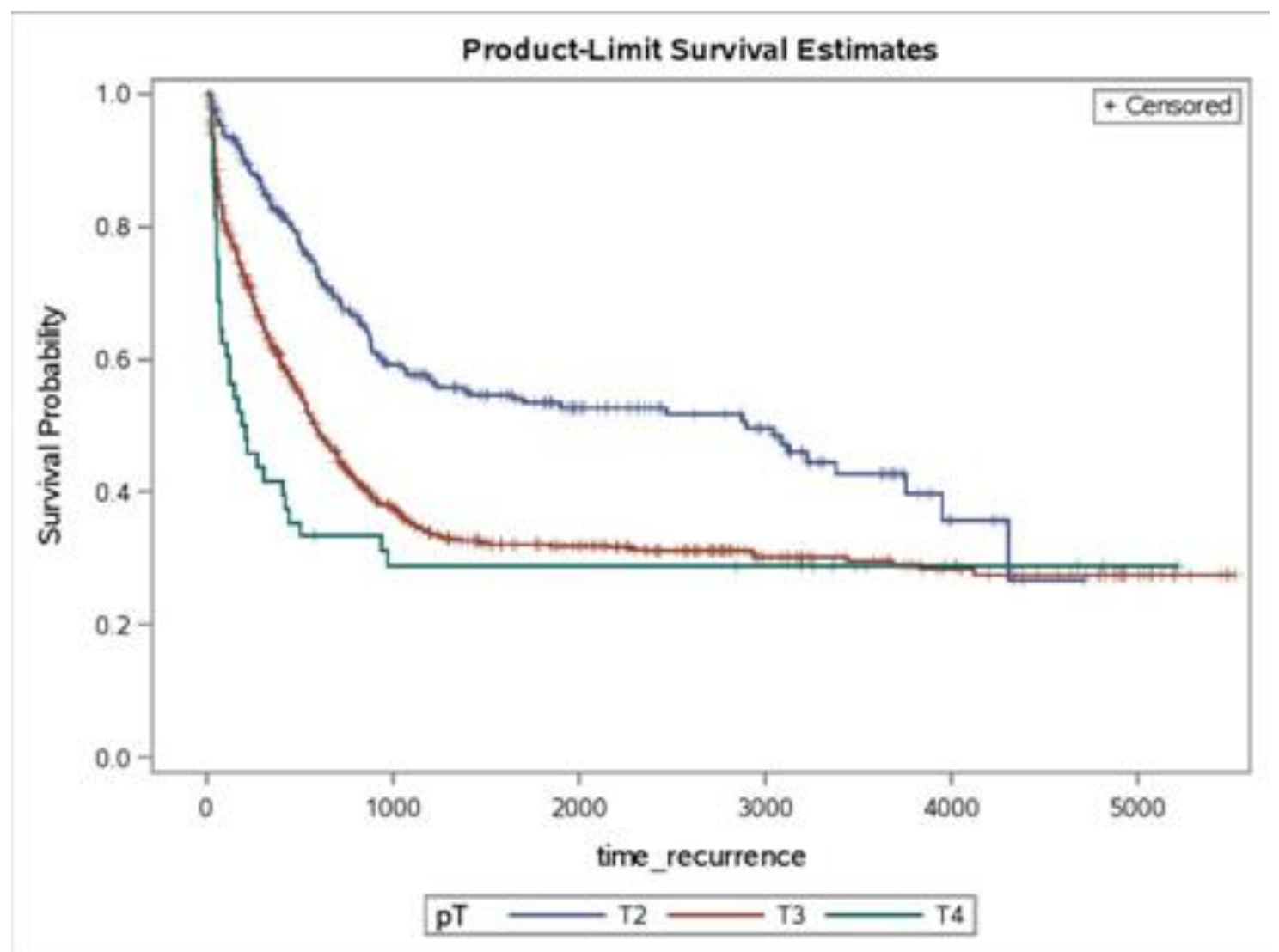


Figure 2: pathological $\mathrm{N}$

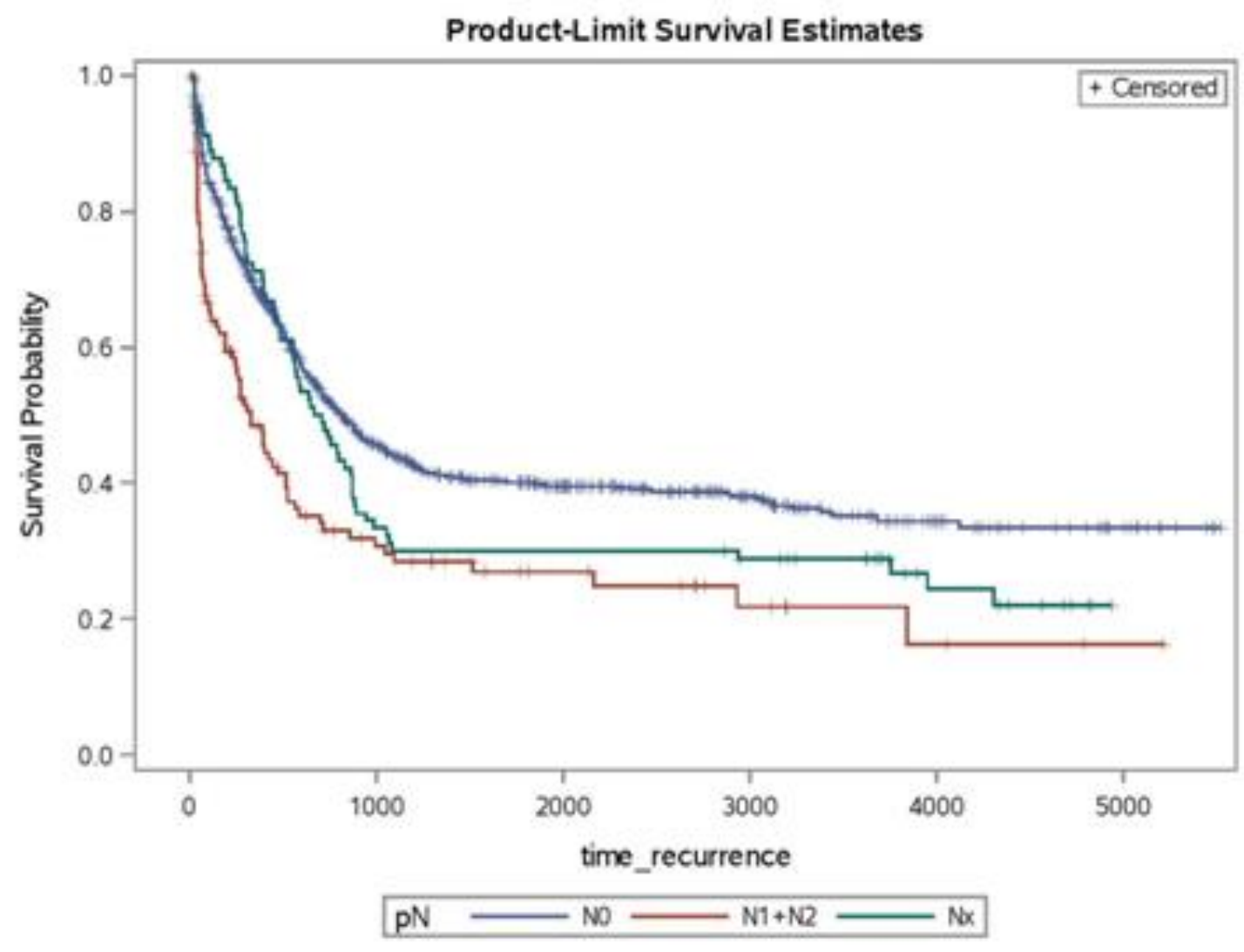


Figure 3: pathological Gleason Score

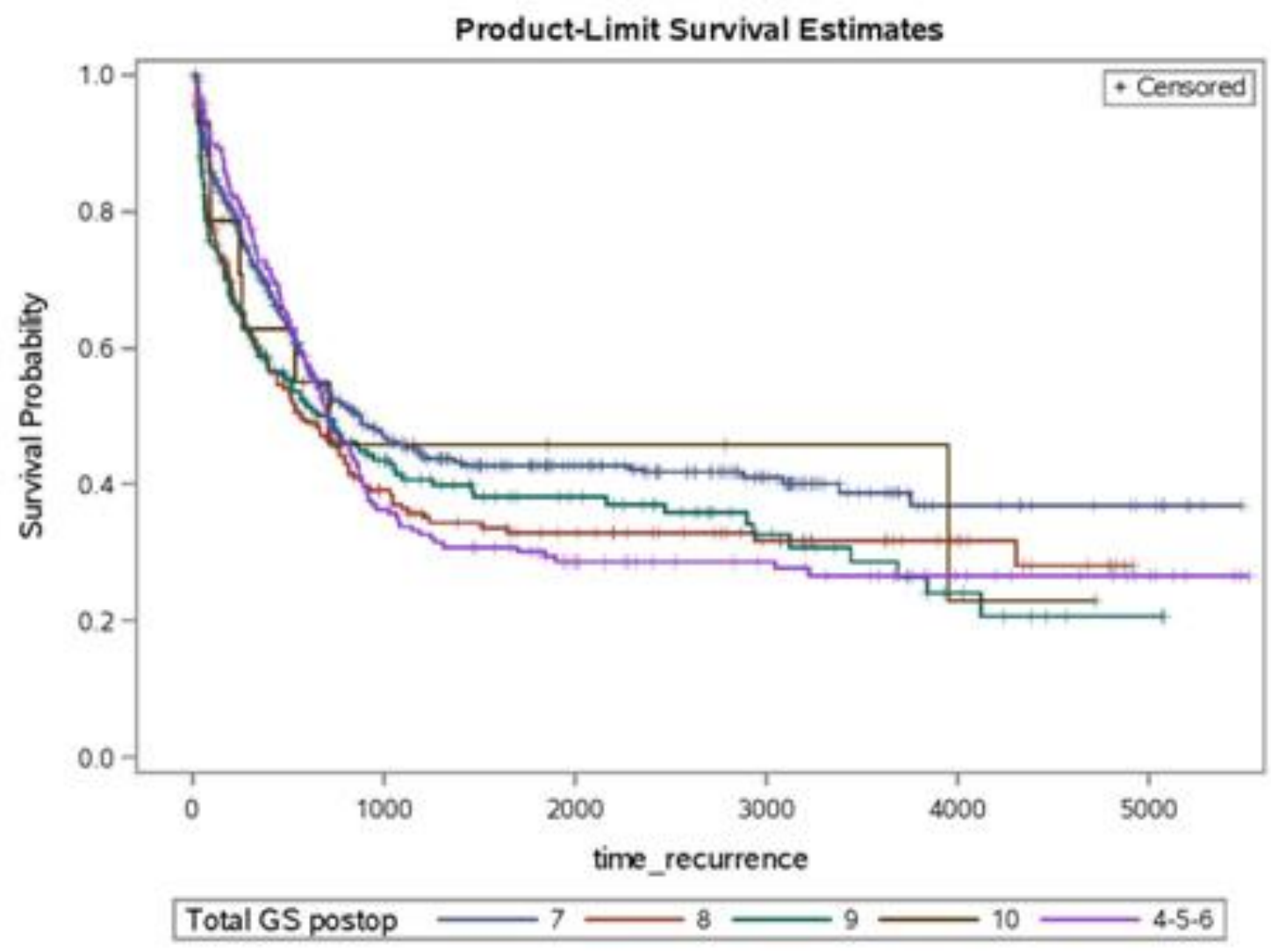


Figure 4: surgical margins

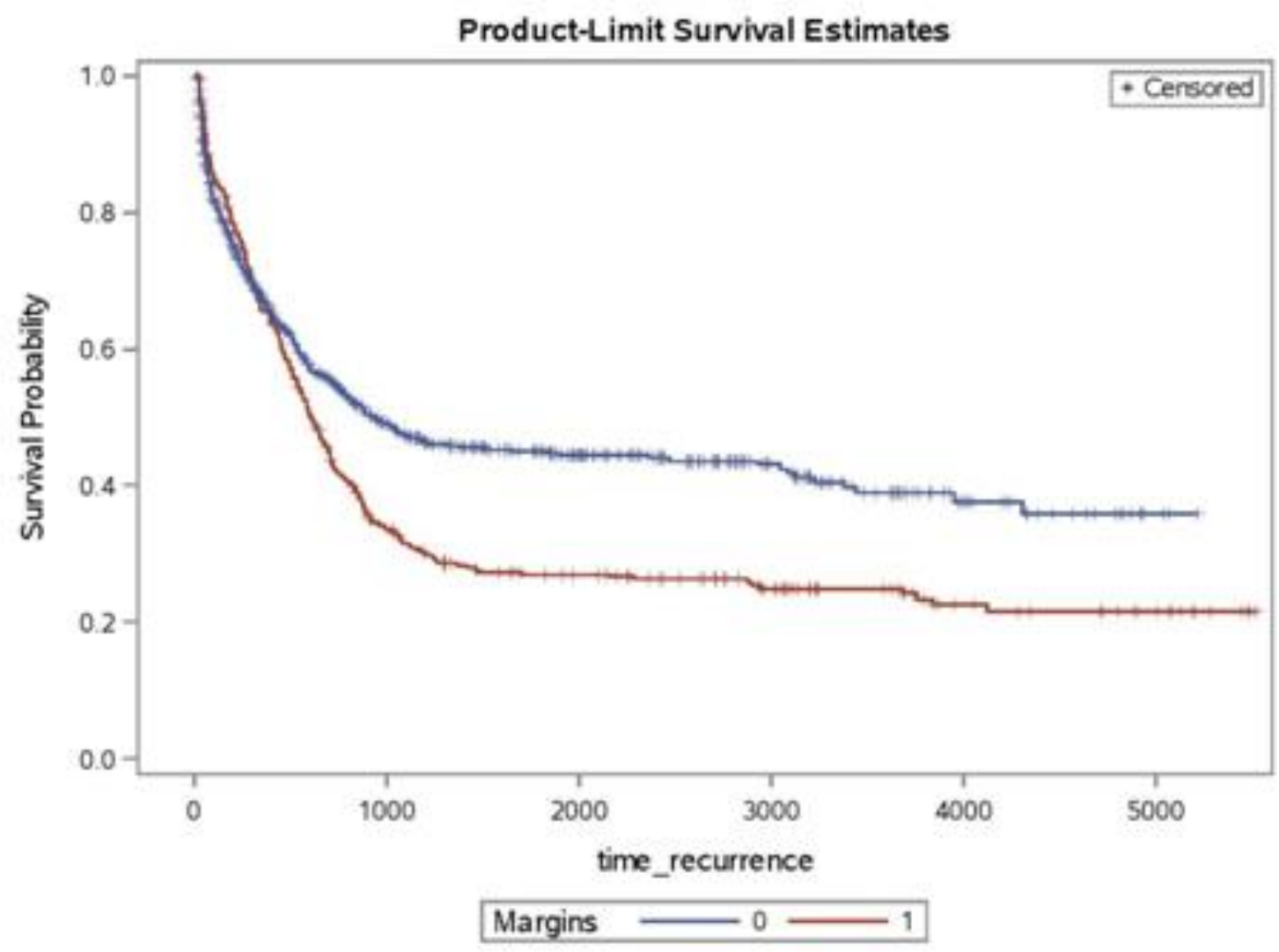


Figure 5: lymphadenectomy

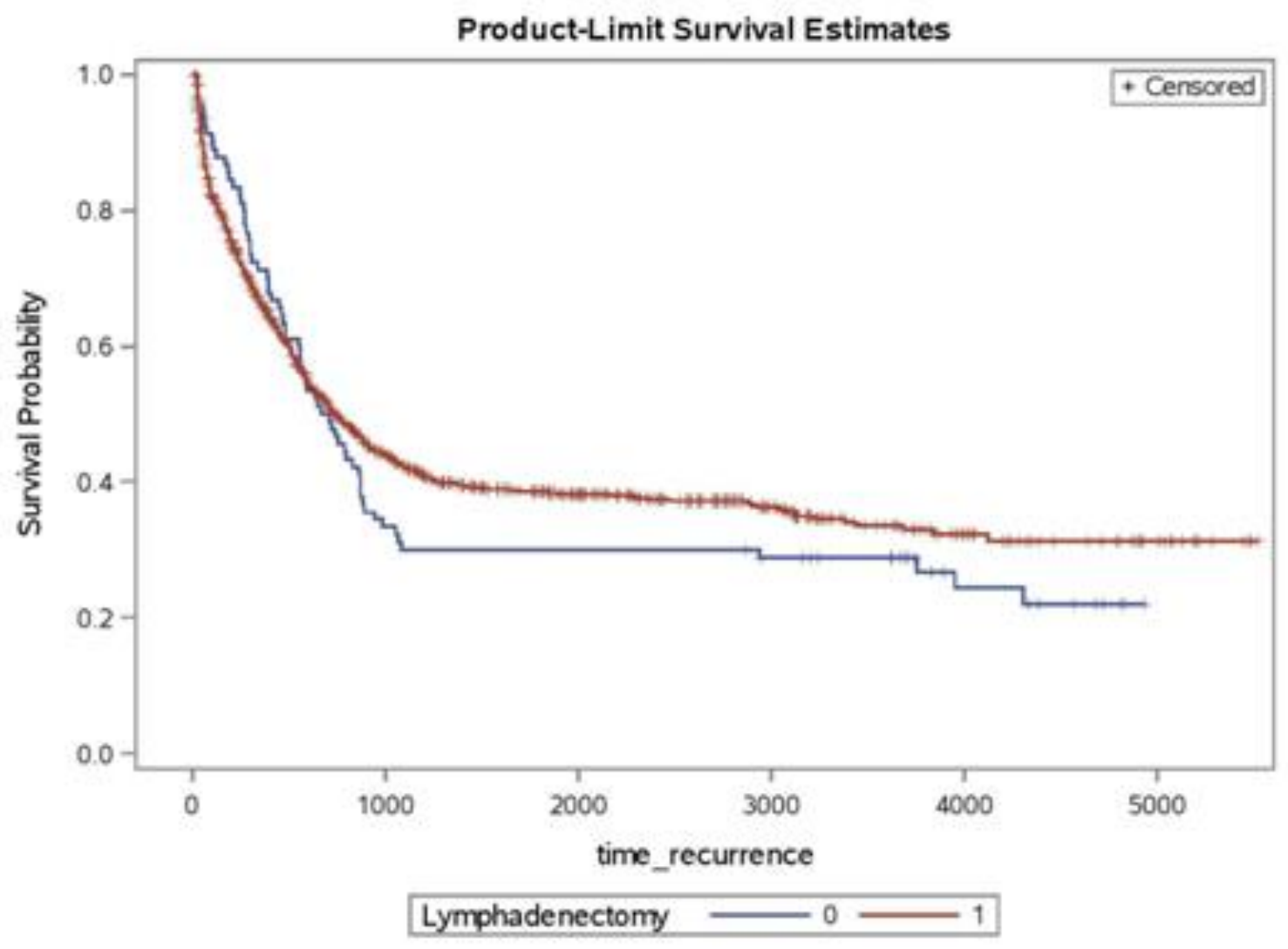




\section{TABLES}

Table 1: preoperative characteristics

\begin{tabular}{|l|l|}
\hline \multicolumn{2}{|c|}{ General preoperative characteristics } \\
\hline Total population & 1114 \\
\hline Mean Age ( \pm SD; range) & $62.0 \pm 8(32-79)$ \\
\hline PSA & $13(1.2 \%)$ \\
\hline$\geq 100$ & $64(5.8 \%)$ \\
\hline $50-99.9$ & $299(26.8 \%)$ \\
\hline $20-49.9$ & $280(25.1 \%)$ \\
\hline $10-19.9$ & $458(41.1 \%)$ \\
\hline$<10$ & \\
\hline cT & $2(0.2 \%)$ \\
\hline cT1b & $235(21.2 \%)$ \\
\hline cT1c & $101(9.1 \%)$ \\
\hline cT2a & $15(1.3 \%)$ \\
\hline cT2b & $218(19.7 \%)$ \\
\hline cT2c & $294(26.5 \%)$ \\
\hline cT3a & $196(17.7 \%)$ \\
\hline cT3b & $48(4.3 \%)$ \\
\hline T4 & \\
\hline Gleason Score & $23(2.2 \%)$ \\
\hline 10 & $99(9.3 \%)$ \\
\hline 9 & $304(28.7 \%)$ \\
\hline 8 & $371(34.9 \%)$ \\
\hline 7 & $264(24.9 \%)$ \\
\hline$\leq 6$ &
\end{tabular}


Table 2: postoperative data

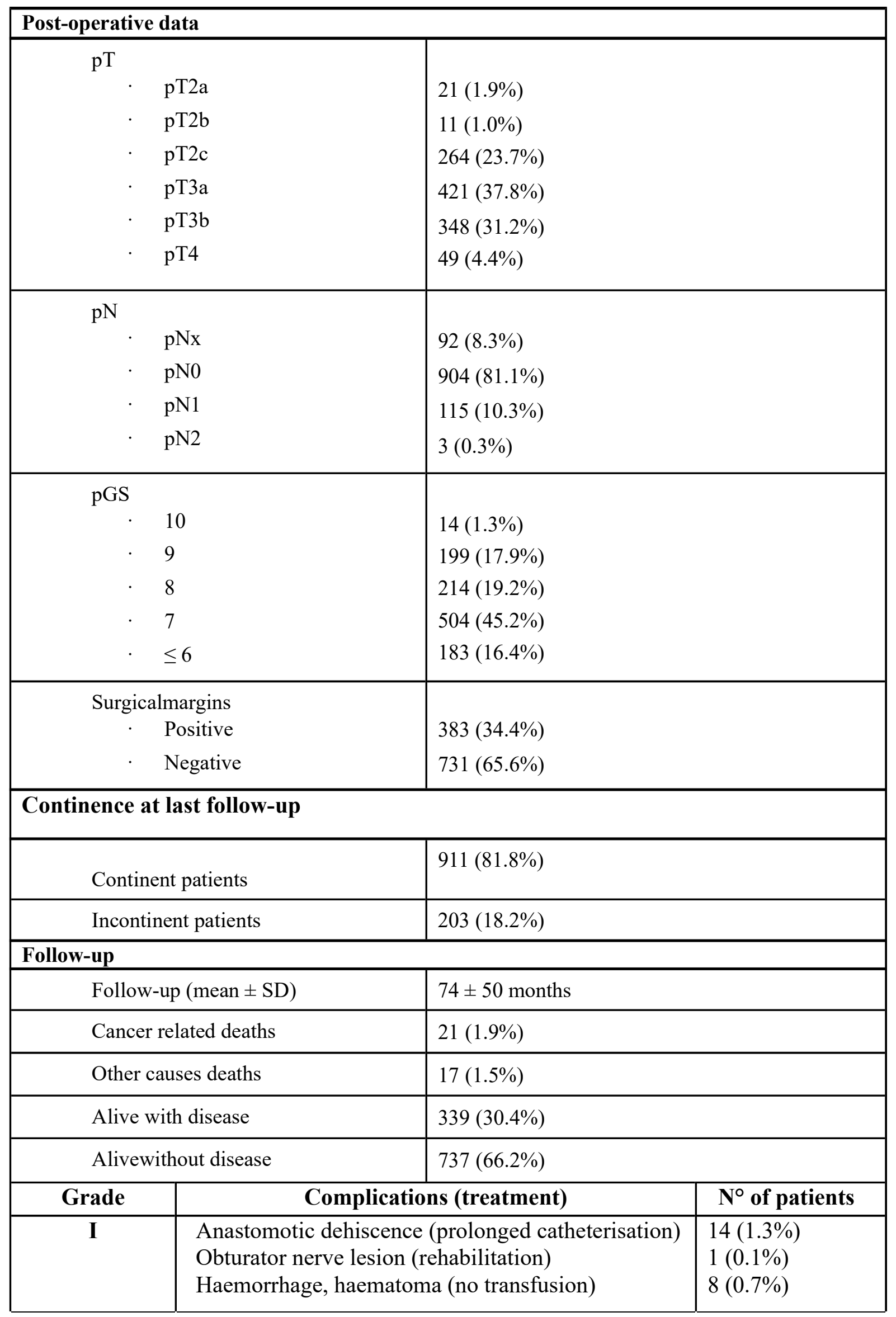




\begin{tabular}{|c|c|c|}
\hline & & Tot. $=23(2.1 \%)$ \\
\hline II & $\begin{array}{l}\text { Urinary tract infections; septicemia (antibiotics) } \\
\text { Haemorrhage (transfusions) } \\
\text { Rectal lesion (medical therapy and NGT) } \\
\text { Paralytic ileus (medical therapy and NGT) } \\
\text { Ileallesion (medical therapy and NGT) }\end{array}$ & \begin{tabular}{|l|}
$3(0.3 \%)$ \\
$132(11.8 \%)$ \\
$5(0.4 \%)$ \\
$4(0.4 \%)$ \\
$1(0.1 \%)$ \\
\\
Tot. $=145$ \\
$(13.0 \%)$ \\
\end{tabular} \\
\hline $\begin{array}{l}\text { III } \\
\text { IIIa } \\
\text { IIIb }\end{array}$ & $\begin{array}{l}\text { Lymphocele, lymphorrhea (percutaneous drainage) } \\
\text { Rectal lesion (colostomy and recanalisation) } \\
\text { Rectal-bladder/urethral fistula (surgery) } \\
\text { Bladder-cutaneous fistula (surgery) }\end{array}$ & $\begin{array}{l}11(1.0 \%) \\
1(0.1 \%) \\
3(0.3 \%) \\
1(0.1 \%) \\
\text { Tot. }=16(1.4 \%)\end{array}$ \\
\hline $\begin{array}{l}\text { IV } \\
\text { IVa } \\
\text { IVb }\end{array}$ & $\begin{array}{l}\text { Transient ischemic attack } \\
\text { Iliac vein lesion }\end{array}$ & $\begin{array}{l}1(0.1 \%) \\
1(0.1 \%) \\
\text { Tot. }=2(0.2 \%) \\
\end{array}$ \\
\hline $\mathbf{V}$ & & 0 \\
\hline \multicolumn{3}{|c|}{ Pathologic data for stPLND and ePLND } \\
\hline & ePLND & stPLND \\
\hline No & $699(89.5 \%)$ & $217(90 \%)$ \\
\hline N1 & $80(10.2 \%)$ & $23(9.5 \%)$ \\
\hline N2 & $2(0.3 \%)$ & $1(0.4 \%)$ \\
\hline Tot. & 781 & 241 \\
\hline
\end{tabular}


Table 3: survival data

\begin{tabular}{|c|c|c|c|}
\hline pT * & Relapse * & Adjuvant therapy* & Follow-up * \\
\hline \multicolumn{4}{|c|}{ pT2 (296) } \\
\hline & \multirow[t]{4}{*}{$\begin{array}{l}\text { Relapse (126) } \\
(42.6 \%)\end{array}$} & $\begin{array}{l}\text { No adjuvant therapy (2) } \\
(1.6 \%)\end{array}$ & $\begin{array}{l}\text { Alive with disease (2) } \\
(100 \%)\end{array}$ \\
\hline & & \multirow[t]{3}{*}{$\begin{array}{l}\text { Adjuvant therapy (124) } \\
(98.4 \%)\end{array}$} & $\begin{array}{l}\text { Cancer deaths (2) } \\
(1.6 \%)\end{array}$ \\
\hline & & & $\begin{array}{l}\text { Alive with disease (38) } \\
(30.7 \%)\end{array}$ \\
\hline & & & $\begin{array}{l}\text { Alive without disease (84) } \\
(67.7 \%)\end{array}$ \\
\hline & \multirow[t]{3}{*}{$\begin{array}{l}\text { No relapse **(170) } \\
(57.4 \%)\end{array}$} & \multirow[t]{2}{*}{$\begin{array}{l}\text { No adjuvant therapy (153) } \\
(90.0 \%)\end{array}$} & $\begin{array}{l}\text { Other causes deaths } \\
\text { (3) }(2.0 \%)\end{array}$ \\
\hline & & & $\begin{array}{l}\text { Alive without disease (150) } \\
(98.0 \%)\end{array}$ \\
\hline & & $\begin{array}{l}\text { Adjuvant therapy (17) } \\
(10.0 \%)\end{array}$ & $\begin{array}{l}\text { Alive without disease (17) } \\
(100 \%)\end{array}$ \\
\hline \multicolumn{4}{|c|}{ pT3 (766) } \\
\hline & \multirow[t]{8}{*}{$\begin{array}{l}\text { Relapse (438) } \\
(57.2 \%)\end{array}$} & \multirow[t]{4}{*}{$\begin{array}{l}\text { No adjuvant therapy (53) } \\
(12.1 \%)\end{array}$} & $\begin{array}{l}\text { Cancer deaths (10) } \\
(18.9 \%)\end{array}$ \\
\hline & & & $\begin{array}{l}\text { Other causes deaths } \\
\text { (1) }(1.9 \%)\end{array}$ \\
\hline & & & $\begin{array}{l}\text { Alive with disease (32) } \\
(60.3 \%)\end{array}$ \\
\hline & & & $\begin{array}{l}\text { Alive without disease (10) } \\
(18.9 \%)\end{array}$ \\
\hline & & \multirow[t]{4}{*}{$\begin{array}{l}\text { Adjuvant therapy (385) } \\
(87.9 \%)\end{array}$} & $\begin{array}{l}\text { Cancer deaths (4) } \\
(1.0 \%)\end{array}$ \\
\hline & & & $\begin{array}{l}\text { Other causes deaths } \\
\text { (3) }(0.8 \%)\end{array}$ \\
\hline & & & $\begin{array}{l}\text { Alive with disease (237) } \\
(61.6 \%)\end{array}$ \\
\hline & & & $\begin{array}{l}\text { Alive without disease (141) } \\
(36.6 \%)\end{array}$ \\
\hline & \multirow[t]{2}{*}{$\begin{array}{l}\text { No relapse ** (328) } \\
(42.8 \%)\end{array}$} & \multirow[t]{2}{*}{$\begin{array}{l}\text { No adjuvant therapy (274) } \\
(83.5 \%)\end{array}$} & $\begin{array}{l}\text { Cancer deaths (3) } \\
(1.1 \%)\end{array}$ \\
\hline & & & $\begin{array}{l}\text { Other causes deaths } \\
(10)(3.6 \%)\end{array}$ \\
\hline
\end{tabular}




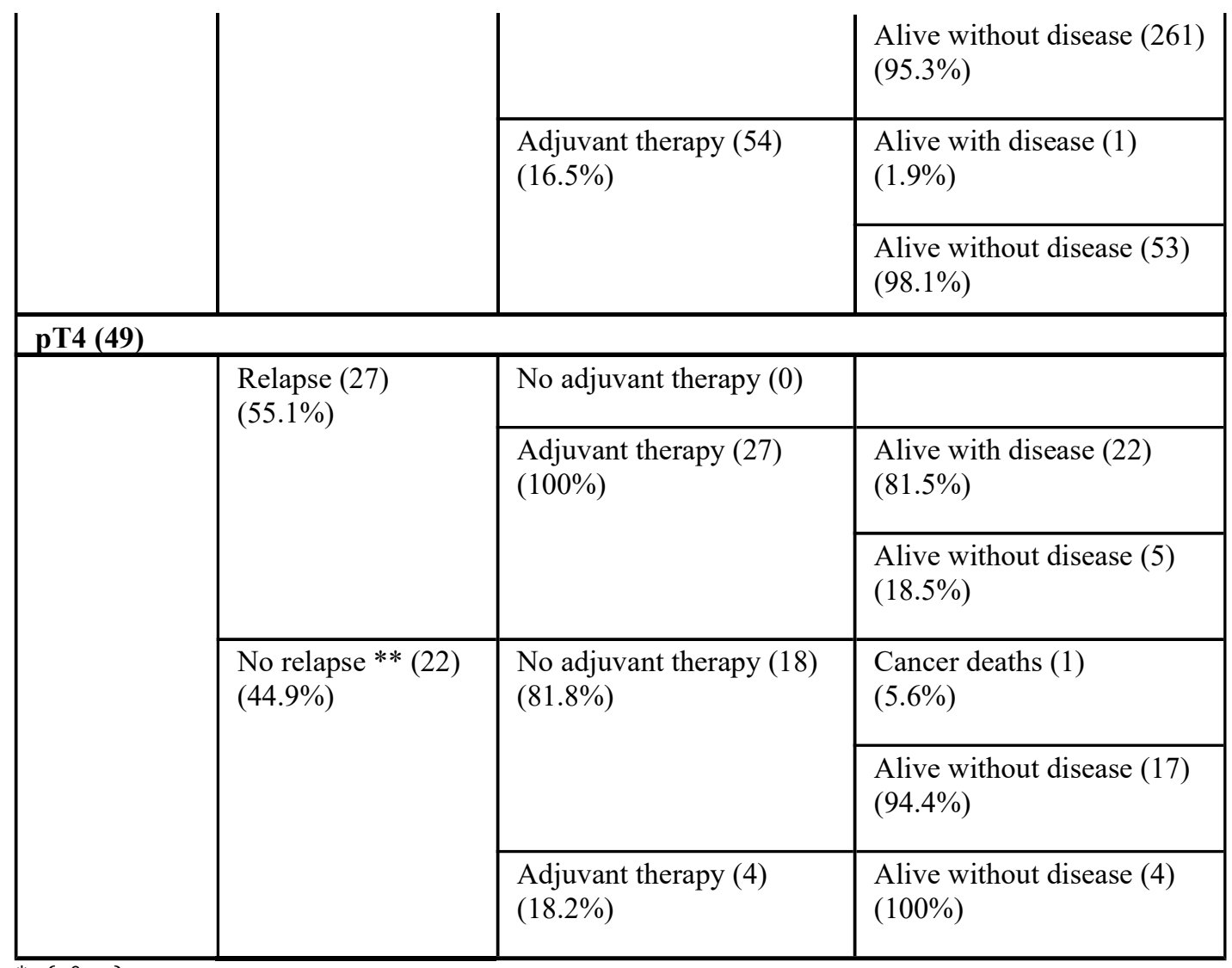

${ }^{*}\left(\mathrm{n}^{\circ} \mathrm{pz}\right)$

** Patients with biochemical recurrence and patients with persistent diesease after surgery 
Table 4: predictors for BR

\begin{tabular}{|c|c|c|c|c|c|}
\hline \multicolumn{3}{|c|}{ Univariate analysis } & \multicolumn{3}{|c|}{ Multivariate analysis } \\
\hline $\begin{array}{l}\text { Age at } \\
\text { prostatectomy }\end{array}$ & $\begin{array}{c}\text { HR (CI 95\%) } \\
0.98(0.97-0.99)\end{array}$ & $<.0001$ & $\begin{array}{l}\text { Age at } \\
\text { Prostatectomy }\end{array}$ & $\begin{array}{c}\text { HR (CI 95\%) } \\
0.98(0.97-0.99)\end{array}$ & 0.0005 \\
\hline $\begin{array}{c}\mathbf{p T} \\
\mathrm{T} 2 * \\
\mathrm{~T} 3 \\
\mathrm{~T} 4\end{array}$ & $\begin{array}{c}\text { HR (CI 95\%) } \\
1 \\
1.8(1.5-2.3) \\
2.4(1.6-3.4)\end{array}$ & $<.0001$ & $\begin{array}{l}\mathbf{p T} \\
\mathrm{T} 2 * \\
\mathrm{~T} 3 \\
\mathrm{~T} 4\end{array}$ & $\begin{array}{c}\text { HR (CI 95\%) } \\
1 \\
1.7(1.4-2.1) \\
2.2(1.5-3.2)\end{array}$ & $<.0001$ \\
\hline $\begin{array}{l}\mathbf{p N} \\
\begin{array}{l}\mathrm{N} 0 * \\
\mathrm{~N} 1+\mathrm{N} 2 \\
\mathrm{Nx}\end{array}\end{array}$ & $\begin{array}{c}\mathrm{HR}(\mathrm{CI} 95 \%) \\
1 \\
1.7(1.4-2.2) \\
1.2(0.9-1.5)\end{array}$ & $<.0001$ & $\begin{array}{l}\mathbf{p N} \\
\begin{array}{l}\mathrm{N} 0 * \\
\mathrm{~N} 1+\mathrm{N} 2 \\
\mathrm{Nx}\end{array}\end{array}$ & $\begin{array}{c}\mathrm{HR}(\mathrm{CI} 95 \%) \\
1 \\
1.6(1.2-2.0) \\
1.2(0.9-1.5)\end{array}$ & 0.0011 \\
\hline $\begin{array}{c}\text { Surgical margin } \\
\text { Negative* } \\
\text { Positive }\end{array}$ & $\begin{array}{c}\text { ns } \mathrm{HR}(\mathrm{CI} 95 \%) \\
1 \\
1.4(1.2-1.6)\end{array}$ & $<.0001$ & $\begin{array}{l}\text { Surgical margins } \\
\text { Negative* } \\
\text { Positive }\end{array}$ & $\begin{array}{c}\mathrm{s} \text { HR (CI 95\%) } \\
1 \\
1.2(1.1-1.5)\end{array}$ & 0.0083 \\
\hline $\begin{array}{l}\text { pGS } \\
\qquad \begin{array}{l}7 * \\
\leq 6 \\
8 \\
9 \\
10\end{array}\end{array}$ & $\begin{array}{c}\text { HR (CI 95\%) } \\
1 \\
1.2(1.0-1.5) \\
1.3(1.1-1.6) \\
1.3(1.0-1.6) \\
1.1(0.5-2.1)\end{array}$ & 0.0465 & & & \\
\hline Lymphadenecto & $\begin{array}{c}\text { omy HR (CI 95\%) } \\
0.9(0.7-1.2)\end{array}$ & 0.4061 & & & \\
\hline PSA pre & $\begin{array}{c}\text { HR (CI 95\%) } \\
.004(1.000-1.007)\end{array}$ & 0.0230 & & & \\
\hline
\end{tabular}

*Reference category 
Table 5: predictors for OS and CSS

\begin{tabular}{|c|c|c|}
\hline \multicolumn{3}{|c|}{ Univariate analysis } \\
\hline $\begin{array}{c}\mathbf{p T} \\
\mathrm{T} 2 * \\
\mathrm{~T} 3 \\
\mathrm{~T} 4\end{array}$ & $\begin{array}{c}\mathrm{HR}(\mathrm{CI} 95 \%) \\
1 \\
2.5(0.7-15.7) \\
2.4(0.3-20.6)\end{array}$ & 0.4836 \\
\hline $\begin{array}{l}\mathbf{p N} \\
\begin{array}{l}\mathrm{N} 0 * \\
\mathrm{~N} 1+\mathrm{N} 2 \\
\mathrm{Nx}\end{array}\end{array}$ & $\begin{array}{c}\text { HR (CI 95\%) } \\
1 \\
5.6(1.9-14.5) \\
1.2(0.3-3.9)\end{array}$ & 0.0025 \\
\hline $\begin{array}{c}\text { § }_{\mathbf{p G S}} \\
\leq 6^{*} \\
7 \\
8 \\
9 \\
10\end{array}$ & $\begin{array}{c}\text { HR (CI 95\%) } \\
1 \\
2.0(0.3-40.8) \\
9.0(1.4-172.9) \\
22.5(4.3-411.4) \\
26.3(1.0-668.4)\end{array}$ & 0.0003 \\
\hline $\begin{array}{l}\text { Surgical margin } \\
\text { Negative* } \\
\text { Positive }\end{array}$ & $\begin{array}{c}\text { s } \operatorname{HR}(\mathrm{CI} 95 \%) \\
1 \\
0.9(0.4-2.1)\end{array}$ & 0.7715 \\
\hline PSA pre & $\begin{array}{c}\text { HR (CI 95\%) } \\
0.99(0.95-1.01)\end{array}$ & 0.3764 \\
\hline
\end{tabular}

*Reference category

$\S_{\text {pGS }}$ was the only variable that maintained statistical significance at multivariate analysis.

Table 6: conrespondance between clinical and pathological stage

\begin{tabular}{|c|c|}
\hline Clinical stage & Pathological stage \\
\hline $\begin{array}{ll}\text { cT1 } & (237) \\
\cdot & \text { cT1b (2) } \\
\cdot & \text { cT1c (235) }\end{array}$ & $\begin{array}{l}\text { pT2 (64); pT3 (173) } \\
\quad \quad \text { pT3a (1); pT3b (1) } \\
\quad \text { pT2a (10); pT2b (5); pT2c (49); pT3a (97); pT3b (74) }\end{array}$ \\
\hline $\begin{array}{ll}\text { cT2 } & (334) \\
\cdot & \text { cT2a }(101) \\
\cdot & \text { cT2b (15) } \\
\cdot & \text { cT2c }(218)\end{array}$ & $\begin{array}{ll}\text { pT2 } & \text { (227); pT3 (107) } \\
. & \text { pT2a (9); pT2b (1); pT2c (20); pT3a (38); pT3b (33) } \\
. & \text { pT2b (4); pT2c (2); pT3a (3); pT3b (6) } \\
. & \text { pT2a (1); pT2b (1); pT2c (189); pT3a (14); pT3b (13) }\end{array}$ \\
\hline $\begin{array}{l}\text { cT3 }(490) \\
\quad \quad \text { cT3a (294) } \\
\cdot \quad \text { cT3b (196) }\end{array}$ & $\begin{array}{l}\text { pT2 (5); pT3 (484); pT4 (1) } \\
\quad \quad \text { pT2a (1); pT2c (4); pT3a (263); pT3b (25); pT4 (1) } \\
. \quad \text { pT3a (1); pT3b (195) }\end{array}$ \\
\hline cT4 (48) & pT4 (48) \\
\hline
\end{tabular}

